\title{
Skin capillary density in pregnancy induced hypertension and normotensive pregnant participants
}

\author{
Mahendra Kumar ${ }^{1 *}$, Vandana Bansal ${ }^{1}$, Pravin N. Mhatre ${ }^{1}$, Uday Khopkar ${ }^{2}$ \\ ${ }^{1}$ Department of Obstetrics and Gynecology, ${ }^{2}$ Department of Dermatology, Seth G. S. Medical College, Mumbai,
} Maharashtra, India

Received: 10 September 2018

Accepted: 06 October 2018

\section{*Correspondence:}

Dr. Mahendra Kumar,

E-mail: mahendrakirankargmc85@gmail.com

Copyright: (c) the author(s), publisher and licensee Medip Academy. This is an open-access article distributed under the terms of the Creative Commons Attribution Non-Commercial License, which permits unrestricted non-commercial use, distribution, and reproduction in any medium, provided the original work is properly cited.

\section{ABSTRACT}

Background: Pre-eclampsia is a vascular related disorder of pregnancy, Despite the increasing research efforts in the field, the etiology and pathogenesis of this disorder remain elusive, resulting in failure to develop specific screening, preventive and treatment strategies. Peripheral vasodilatation and angiogenesis are critical components of physiological adaptation in normal pregnancy. Women who have later developed preeclampsia had significant structural capillary density rarefaction early in the pregnancy before the onset of preeclampsia.

Methods: Case control, comparative study was carried out at our institute. 30 pregnant participants were recruited in each group after satisfying the inclusion criteria. Data was collected by using dermatoscope (200X magnification). Statistical analysis was done by non-parametric test- Mann-Whitney test as blood pressure was not normally distributed among participants. Spearman's correlation coefficient was used to make correlation between skin capillary densities and blood pressures.

Results: On applying Mann-Whitney test, mean rank for systolic and diastolic blood pressure at 20 weeks for both groups were not significant statistically, mean rank for systolic and diastolic blood pressure between 28-36 weeks of gestation for both groups were significant statistically. After testing, skin capillary density came significantly less in hypertensive group as compare to normotensive pregnant participant of same gestational ages. Spearman's correlation coefficient came negative for systolic and positive for diastolic blood pressure at 28-36 weeks of gestation.

Conclusions: Authors conclude that estimating the skin capillary density provides a potentially useful clinical marker in the prediction of preeclampsia and dermatoscope is an especially attractive clinical tool.

Keywords: Dermatoscope, Pregnancy induced hypertension, Skin capillary density

\section{INTRODUCTION}

Pre-eclampsia is a vascular related disorder of pregnancy which presents clinically after 20 weeks of gestation as newly recognized hypertension and proteinuria. It complicates $3 \%-7 \%$ of all pregnancies worldwide and is a major cause of maternal and neonatal mortility and morbidity. ${ }^{1}$

Despite the increasing research efforts in the field, the etiology and pathogenesis of this disorder remain elusive, resulting in failure to develop specific screening, preventive and treatment strategies; however defective placentation is the underlying pathology in many cases. ${ }^{2,3}$

Defective placentation results in a dysfunctional uteroplacental circulation and augments placental oxidative stress. Pathological studies show abnormal development of an ischemic placenta with high resistance vasculature which cannot deliver an adequate blood supply to the fetoplacental unit. There is increasing evidence of widespread microcirculatory and endothelial 
cell abnormality in this syndrome. Dysfunctional endothelial cells produce altered quantities of vasoactive mediators, which lead to imbalance towards vasoconstrictors. Reactive oxygen species and cytokines released from the ischemic placenta trigger a systemic oxidative stress and contribute to exaggerated systemic inflammatory reaction in pre-eclampsia. ${ }^{4}$

Hypoxic oxidative stress and inflammatory stimuli provoke the release of anti-angiogenic factors via Nuclear Factor Kappa-light-chain enhancer of activated B cell (NK-kB) pathway. Soluble FMS like tyrosine kinase 1 (sFLT1), a circulating truncated form of vascular endothelial growth factor (VEGF) receptor, binds and reduces levels of VEGF and placental growth factor (PIGF) in maternal circulation.

VEGF is not only an angiogenic factor but also maintains endothelial fenestrae formation. VEGF antagonists are increased and VEGF factor decreases in circulation thereby inhibiting angiogenesis and vasodilatation. Soluble endothelin, a Transforming growth factor- beta (TGF-beta) co receptor, one of the anti-angiogenic factors that enhance vascular permeability, is also affected. ${ }^{4}$

Peripheral vasodilatation and angiogenesis are critical components of physiological adaptation in normal pregnancy. ${ }^{5}$ A reduction in capillary density is known to occur in many tissues in the participants with essential hypertension in established as well as early disease. Decreased capillary density may play a role in increasing peripheral resistance. Women who have later developed preeclampsia had significant structural capillary density rarefaction early in the pregnancy before the onset of preeclampsia. Maximally capillary density remains significant lower in the hypertensive subjects than in the normotensive subjects. ${ }^{6}$

Therefore, quantifying capillary rarefaction in the early pregnancy could be helpful in the clinical prediction of PIH. Current study is designed to assess skin capillary density in PIH and normal pregnancy, to investigate the correlation, whether defective angiogenesis reflected by decreased capillary density results in syndrome of preeclampsia. The objectives of the present study were to compare skin capillary density of pregnancy induced hypertensive participants and normotensive pregnant participants between 28 weeks to 36 weeks of gestation. And to investigate the correlation, whether defective angiogenesis reflected by decreased capillary density results in syndrome of pre-eclampsia.

\section{METHODS}

This case control, comparative study was carried out at our institute. Pregnant women were enrolled in the study after satisfying the inclusion criteria. Written, informed and valid consents were taken. Data was collected during the gestational period of 28-36 weeks of each participant. Pregnant participants were divided into 2 groups- one having PIH and other normotensive. The essential age, parity and gestational age were matched in both the groups. Sample size of present study was $60 \quad(30$ normotensive participants and $30 \mathrm{PIH}$ participants).

\section{Inclusion criteria}

- $\quad$ Pregnant participants between 20-35 years of age.

- Gestational age from 28 weeks to 36 weeks of gestation.

- Participants having blood pressure more than 140 $\mathrm{mmHg}$ - systolic and $90 \mathrm{mmHg}$ - diastolic,

Associated with-

(a) Proteinuria ->300mg/24hours OR Urine Dipstick more than $1+$ positive.

(b) Thrombocytopenia - Platelets - <1 lacs /micro liter.

(c) Creatinine - >1.1mg/dl.

(d) Serum transaminases levels twice of normal values (0-35 IU/L).

- Registered before 20 weeks of gestation, in order to rule out chronic hypertension.

- $\quad$ Singleton pregnancy.

\section{Exclusion criteria}

- Pregnant women who had pregnancy induced hypertension in previous pregnancy.

- Pregnant women having essential hypertension.

- Pregnant women having systemic disease like atherosclerosis, cardiovascular disease, renal disease, vascular disease, thyroid disorder.

- Pregnant women having other related or unrelated high-risk factors.

- Pregnant women having malformed fetus.

- Pregnant women not satisfying inclusion criteria.

\section{Study procedure}

In present study, skin capillary density was taken in skin department of our institute. Informed and written consent were taken. Subjects were made to seat with their left forearm and hand supported at heart level. Blood pressure was recorded before the procedure after making the participant rested for at least 10 minutes in a temperaturecontrolled room.

The procedure was carried out using an Ultra cam Video Microscope from Derma India. This was a specialized magnifying instrument capable of $200 \mathrm{X}$ and $50 \mathrm{X}$ magnification.

Authors used 200X magnification for present study. It has three light sources: white, ultraviolet and polarized. We were seeing for capillary vessels and thus using polarized light in particular but comparing in all three.

The nail bed (middle phalanx of non-dominant hand) was visualized under the said magnification. It is a non- 
invasive procedure and the nail bed structure is observed under self-illumination. An area of $1 \mathrm{~mm}$ square is observed, and capillary count is done, the same was photographed.

\section{Statistical analysis}

Statistical analysis was done by non-parametric testMann-Whitney test as blood pressure was not normally distributed among participants.

To make correlation between skin capillary densities and between blood pressures, Spearman's correlation coefficient was used.

\section{RESULTS}

60 pregnant participants were included in present study after satisfying the inclusion criteria. Skin capillary density was measure and data were evaluated, which are as follows-

\section{Mean age}

Table 1: Age distribution among both groups.

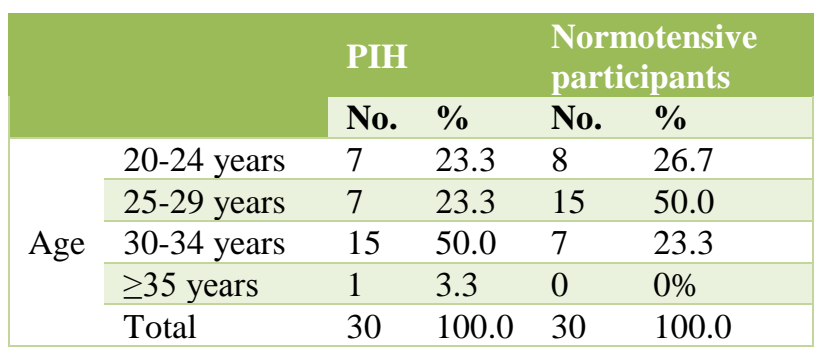

In present study mean age of the participants was 28 years, maximum numbers of PIH participants were between age group 30-34 years and maximum numbers of normotensive patients were between age group of 25 29 years.

Difference in age of participants in both groups was not significant statistically (P value-0.167).

\section{Gestational age}

Table 2: Distribution of gestational age among both groups.

\begin{tabular}{|c|c|c|}
\hline Range of gestational age (weeks) & Normal & PIH \\
\hline $28-30$ & 2 & 2 \\
\hline $30-32$ & 3 & 3 \\
\hline $32-34$ & 15 & 10 \\
\hline $34-36$ & 10 & 15 \\
\hline Total & 30 & 30 \\
\hline
\end{tabular}

Maximum number in normotensive was in 32-34 weeks of gestation, whereas in PIH was in 34-36 weeks of gestation.

\section{Parity}

Table 3: Distribution of gravidity among both groups

\begin{tabular}{|clllll|} 
& & PIH & \multicolumn{3}{c|}{ Normotensive } \\
& & No. & \% & No. & \% \\
\hline \multirow{3}{*}{ Gravidity } & Primigravida & 15 & 50 & 14 & 46.7 \\
\cline { 2 - 6 } & Multigravida & 15 & 50 & 16 & 53.3 \\
\cline { 2 - 6 } & Total & 30 & 100 & 30 & 100.0 \\
\hline
\end{tabular}

Multigravida $(51.7 \%)$ was more in present study as compare to Primigravida (48.3\%).

Among PIH both Primigravida and Multigravida were same, but in normotensive group Multigravida were marginally more. In both the group, difference in parity was not statistically significant ( $P$ value- 0.796$)$.

\section{Blood pressure measurements}

Table 4: Blood pressure at 20 weeks and 28-36 weeks among both groups.

\begin{tabular}{|l|l|l|l|l|}
\hline \multirow{2}{*}{ SBP at 20 weeks } & PIH & N & Mean & SD \\
\hline \multirow{2}{*}{ DBP at 20 weeks } & No & 30 & 111.93 & 4.653 \\
\cline { 2 - 5 } & Yes & 30 & 710.87 & 4.125 \\
\cline { 2 - 5 } SBP at 28-36 weeks & No & 30 & 72.80 & 4.920 \\
\cline { 2 - 5 } & Yes & 30 & 144.87 & 6.426 \\
\hline \multirow{2}{*}{ DBP at 28-36 weeks } & Yes & 30 & 112.87 & 5.476 \\
\hline & No & 30 & 77.93 & 4.760 \\
\hline
\end{tabular}

Mean SBP at 20 weeks among hypertensive and normotensive were $111.93 \mathrm{mmHg}$ and $110.87 \mathrm{mmHg}$ respectively, Whereas DBP at 20 weeks among hypertensive and normotensive were $75.07 \mathrm{mmHg}$ and $72.80 \mathrm{mmHg}$ respectively.

Mean SBP between 28-36 weeks among PIH and normotensive were $144.87 \mathrm{mmHg}$ and $112.87 \mathrm{mmHg}$ respectively, Whereas DBP between 28-36 weeks among $\mathrm{PIH}$ and normotensive were 93.40 and 77.93 respectively.

Mean skin capillary density for PIH pregnant participants were 8.37 capillary/ $\mathrm{mm}$ square whereas for normotensive pregnant participants were 12.00 capillary/ mm square.

For distribution of blood pressure among participants Shapiro-Wilk test was applied. Test came as statistically significant, which means blood pressures among participants were not distributed normally.

As our sample was not normally distributed, nonparametric test was required to know the significance of data. Mann-Whitney test is a nonparametric test of Null hypothesis, that does not require normal distributions, and it is nearly as efficient as the t-test on Normal distributions. 
Table 5: Mann-Whitney test for blood pressure at 20 weeks.

\begin{tabular}{|lllll|}
\hline \multirow{2}{*}{$\begin{array}{l}\text { SBP at } 20 \\
\text { weeks }\end{array}$} & Yes & 30 & 32.23 & 967.00 \\
\cline { 2 - 5 } Do & No & 30 & 28.77 & 863.00 \\
\hline 20 weeks & Yes & 30 & 33.63 & 1009.00 \\
\cline { 2 - 5 } & No & 30 & 27.37 & 821.00 \\
\hline
\end{tabular}

Mean rank for SBP at 20 weeks for hypertensive and normotensive participant was 32.23 and 28.77 respectively, whereas mean rank for DBP at 20 weeks for hypertensive and normotensive participants was 33.63 and 27.37 respectively.

SBP at 20 weeks of gestation wasn't statistically significant ( $\mathrm{P}$ value- 0.270). It means blood pressure among both groups at 20 weeks was equally distributed and there was no difference in them. DBP also at 20 weeks of gestation came not statistically significant ( $p$ value- 0.117). It means blood pressure among both groups at 20 weeks was equally distributed and there was no difference in them.

Table 6: Mann-Whitney test for blood pressure between 28-36 weeks.

\begin{tabular}{lllll} 
& PIH & No. Mean rank & Sum of ranks \\
SBP at 28- & Yes & 30 & 45.50 & 1365.00 \\
\cline { 2 - 5 } 36 weeks & No & 30 & 15.50 & 465.00 \\
\hline $\begin{array}{l}\text { DBP at 28- } \\
\text { 36 weeks }\end{array}$ & Yes & 30 & 45.50 & 1365.00 \\
\cline { 2 - 5 } & No & 30 & 15.50 & 465.00 \\
\hline
\end{tabular}

Mean rank for SBP between 28-36 weeks of gestation for $\mathrm{PIH}$ and normotensive participant was 45.50 and 15.50 respectively, whereas mean rank for DBP at 28-36 weeks for PIH and normotensive participants was 45.50 and 15.50 respectively. After testing, SBP between 28-36 weeks of gestation was statistically significant ( $\mathrm{P}$ value$0.0001)$, that means there was significant difference in SBP among both group between 28-36 weeks of gestation. DBP also at 28-36 weeks of gestation was statistically significant ( $P$ value- 0.0001$)$, that means there was significant difference in DBP among both groups between 28-36 weeks.

\section{Skin capillary density}

Table 7: Distribution of skin capillary density among both groups.

\begin{tabular}{lllll} 
& PIH & N & $\begin{array}{l}\text { Mean } \\
(\mathrm{mm} / \text { square })\end{array}$ & SD \\
$\begin{array}{lllll}\text { Skin capillary } \\
\text { density in mm } \\
\text { square }\end{array}$ & Yes & 30 & 8.37 & 1.217 \\
\cline { 3 - 5 } & No & 30 & 12.00 & 1.365 \\
\hline
\end{tabular}

In normotensive groups capillary densities were between 10-16 capillaries/ mm square (mean- 12.00 capillaries/mm square), whereas in PIH groups it was between 6-11 capillaries/mm square (mean- 8.37 capillaries/mm square).

Table 8: Mann-Whitney test for skin capillary density between 28-36 weeks of gestational age.

\begin{tabular}{|c|c|c|c|c|}
\hline \multirow{3}{*}{$\begin{array}{l}\text { Skin capillary } \\
\text { density in mm }\end{array}$} & PIH & $\mathbf{N}$ & Mean rank & Sum of ranks \\
\hline & Yes & 30 & 16.02 & 480.50 \\
\hline & No & 30 & 44.98 & 1349 \\
\hline
\end{tabular}

Mean rank for Capillary density among group, PIH and normotensive was 16.02 and 44.98 receptively, which signifies that capillary density among PIH group was less as compare to normotensive pregnant participants between same gestational ages. After testing, skin capillary density came significantly less in hypertensive group ( $\mathrm{P}$ value-0.0001) as compare to normotensive pregnant participant of same gestational ages. This means skin capillary density decreased in hypertensive pregnant patient. This was our first objective.

Correlation of skin capillary density and blood pressure: After this we tested for correlation of skin capillary density with blood pressure. Since our data were not normally distributed, Spearman's rho test was applied.

Table 9: Correlation between blood pressure and skin capillary density.

\begin{tabular}{|c|c|c|c|}
\hline \multicolumn{2}{|c|}{ Spearman's rho } & $\begin{array}{l}\text { SBP at } \\
28-36 \\
\text { weeks }\end{array}$ & $\begin{array}{l}\text { DBP at } 28 \text { - } \\
36 \text { weeks }\end{array}$ \\
\hline \multirow{3}{*}{$\begin{array}{l}\text { Skin capillary } \\
\text { density in mm } \\
\text { square }\end{array}$} & $\begin{array}{l}\text { Correlation } \\
\text { coefficient }\end{array}$ & -0.205 & 0.162 \\
\hline & Sig.(2-tailed) & 0.277 & 0.391 \\
\hline & $\mathrm{N}$ & 30 & 30 \\
\hline
\end{tabular}

After testing, spearman's correlation coefficient came 0.205(negative) for SBP at 28-36 weeks. Negative value signifies that on increasing SBP, skin capillary density decreases, whereas low value (0.205) signified that both SBP and skin capillary density are weak monotonous.

Spearman's correlation coefficient came +0.162 (positive) for DBP at 28-36 weeks of gestation. Positive value signifies that on increasing DBP skin capillary density increases, whereas low value (0.162) signifies that both DBP and skin capillary density are weak monotonous, which means skin capillary density is weakly correlated with SBP and DBP. This was our second objective.

Reason may be the small sample size of present study for weak correlation between skin capillary density and blood pressures.

\section{DISCUSSION}

Recent studies have shown that skin capillary density is the new variable for prediction of hypertensive disorders. 
Various studies were conducted in non-pregnant participants. In 1999, Antonios et al stated that "a reduction in the density of capillaries (rarefaction) is known to occur in many tissues in patients with essential hypertension. This rarefaction may play a role in increasing peripheral resistance." They found that mean capillary density at baseline (before venous congestion) was significantly lower in the hypertensive subjects than in the normotensive controls. ${ }^{6}$

Similarly, Debbab $\mathrm{H}$ et al stated that "Non-diabetic hypertensive patients, capillary density are reduced in association with a cluster of cardiovascular risk factors involving tobacco consumption and obesity". They found that baseline and maximal capillary densities were significantly lower in untreated than in treated hypertensive patients and normotensive. ${ }^{7}$

Antonios et al also found significantly lower skin capillary density in healthy normotensive individuals with a familial predisposition to essential hypertension. ${ }^{8}$

Similar studies related to pregnancy, like Kvehaugen etal9 stated "Women having undergone pregnancies complicated by preeclampsia, and possibly offspring of preeclampsia pregnancies, exhibit an increased risk of cardiovascular diseases (CVDs) later in life." They found that - endothelial function in women and children of preeclamptic, SGA (small for gestational age) pregnancies are impaired several years subsequent to the pregnancy. In addition, high concentrations of circulating antiangiogenic and inflammatory proteins persist from delivery to 5 to 8 years postpartum in the mother with a history of preeclampsia compared with women with a history of uncomplicated pregnancy. This finding supports the concept of trans-generational risk of cardiovascular disease after preeclampsia.

Another study conducted on animal model, Fraser et al hypothesized that- "reduced uterine artery perfusion pressure would be associated with capillary rarefaction and impaired capillary perfusion, which would be more pronounced in the pregnant state." 10

\section{Mean age}

Table 10: Comparison of age with other studies.

\begin{tabular}{|c|c|c|}
\hline Studies & No. & Mean age (years) \\
\hline Hasana et $\mathrm{al}^{5}$ & 44 & 30 \\
\hline Nama $V$ et al ${ }^{11}$ & 322 & 32.2 \\
\hline Antonios et $\mathrm{al}^{8}$ & 322 & 32.2 \\
\hline Rusavy $\mathrm{Z}$ et $\mathrm{al}^{12}$ & 31 & 32 \\
\hline Present study & 60 & 28 \\
\hline
\end{tabular}

As compared to other similar studies, our participants were younger, which was expected in Indian population as compare to western countries. Whereas in study conducted by Nama V et al Antonios et al, Rusavy Z et al mean age was around 32 years. ${ }^{8,11,12}$

\section{Gestational age}

Table 11: Comparison of gestational age with other studies.

\begin{tabular}{|lll|}
\hline Studies & No. & Mean gestational age (weeks) \\
\hline Hasana et $\mathrm{al}^{5}$ & 44 & $21-40$ \\
\hline${\text { Antonios et } \mathrm{al}^{8}}^{\mathrm{S}}$ & 322 & 35.6 \\
\hline Rusavy Z et al & 31 & 36.5 \\
\hline Present study & 60 & 33.8 \\
\hline
\end{tabular}

In both group, difference in gestational age was not statistically significant ( $P$ value- 0.113 ). In present study, mean gestational age of the participants were 33.8 weeks, other studies showed that hypertensive pregnant participants were of same gestational age i.e. 35-36 weeks.

\section{Parity}

Table 12: Comparison of gravidity with other studies.

\begin{tabular}{|c|c|c|}
\hline Studies & No. & Primigravida (\%) \\
\hline Hasana et $\mathrm{al}^{5}$ & 44 & 100 \\
\hline Nama V et al ${ }^{11}$ & 322 & 100 \\
\hline Antonios et $\mathrm{al}^{8}$ & 322 & - \\
\hline Rusavy $\mathrm{Z}$ et $\mathrm{al}^{12}$ & 31 & 80.6 \\
\hline Present study & 60 & 48.3 \\
\hline
\end{tabular}

In other studies, maximum participants were Primigravida as high as $80 \%$. In present study Primigravida participants were $48.3 \%$ and Multigravida were $51.7 \%$. As compare to other studies, Primigravida were less in the present study. Multigravida is much more common in Indian population as compare to western countries, which may be the reason for that.

\section{Blood pressure measurements}

Table 13: Comparison of mean systolic and diastolic blood pressure with other studies.

\begin{tabular}{|c|c|c|c|}
\hline Studies & No. & $\begin{array}{l}\text { Mean SBP } \\
(\mathrm{mmHg}) \text { of } \\
\text { PIH }\end{array}$ & $\begin{array}{l}\text { Mean DBP } \\
(\mathrm{mmHg}) \text { in } \\
\text { PIH }\end{array}$ \\
\hline Hasana et-al $^{5}$ & 44 & 138 & \\
\hline Nama $V$ et-al ${ }^{11}$ & 322 & 113 & 71 \\
\hline Antonios et-al $^{8}$ & 322 & 106.7 & 62.4 \\
\hline Present study & 60 & 144 & 93 \\
\hline
\end{tabular}

According to Hasana et al, Women with pre-eclampsia had significantly increased SBPs and DBPs compared with healthy pregnant women matched for maternal and gestational age, and non-pregnant age-matched controls: pre-eclampsia-138/88mmHg; healthy pregnancy108/67mmHg; non-pregnant controls-107/ 69mmHg. ${ }^{5}$

According to Nama et-al11, normotensive pregnant women had increased in both SBPs and DBPs (P value- 
0.001 and $\mathrm{P}$ value- 0.001 , respectively) which wasn't significant at 20-24 weeks and 27-32 weeks of gestation as compare to baseline. Compared with baseline at 11-16 weeks of gestation, the increase in SBPs and DBPs was significant at all visits in women who developed preeclampsia.

Nama et al and Hasana et al, studies were comparable to the present study. ${ }^{11,15}$

\section{Skin capillary density}

According to Khaled M. Hasana "Both BCD (Basal capillary density) and MCD (maximum capillary density) with venous congestion were significantly lower in women with pre-eclampsia than in healthy normotensive pregnant women of similar gestational age and nonpregnant healthy controls. Results were similar to the present study. 5

Similarly, Antonios et-al study has same results to the present study. $^{8}$ In their study also, there was a significantly $(15 \%)$ lower mean capillary density in the index subjects at baseline than in the controls 67capillary/field as compare to 79 capillaries per field ( $P$ Value $=0.008)$. After two minutes of venous congestion, maximum capillary density remained significantly lower (by 20\%) in the index group than in the controls 74 capillary/field as compare to 93 capillaries per field ( $\mathrm{P}$ Value $=0.0005)^{\prime}$.

In study conducted by Nama et al, similar results were observed. Significant reduction in maximal capillary density at the 20-24 weeks (mean change 7.0 capillaries per field; $95 \%$ confidence interval ( $\mathrm{P}$ value -0.015 ), was around 7-21 weeks before the onset of preeclampsia."11 Rusavy $\mathrm{Z}$ et al study had functional capillary density which was comparable to the present study. ${ }^{12}$

As compared to others similar studies number of skin capillary was less in the present study. Black colored skin and more amounts of scales in skin in Indian populations can be the reason for less number of skin capillaries.

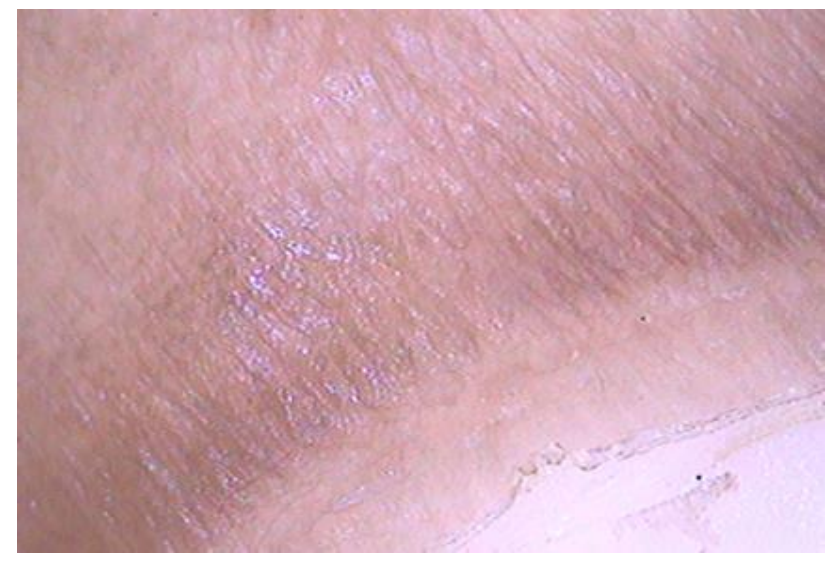

Figure 1: Nail bed under dermatoscope without oil.
On application of oil like- glycerin on nail bed increases resolution.

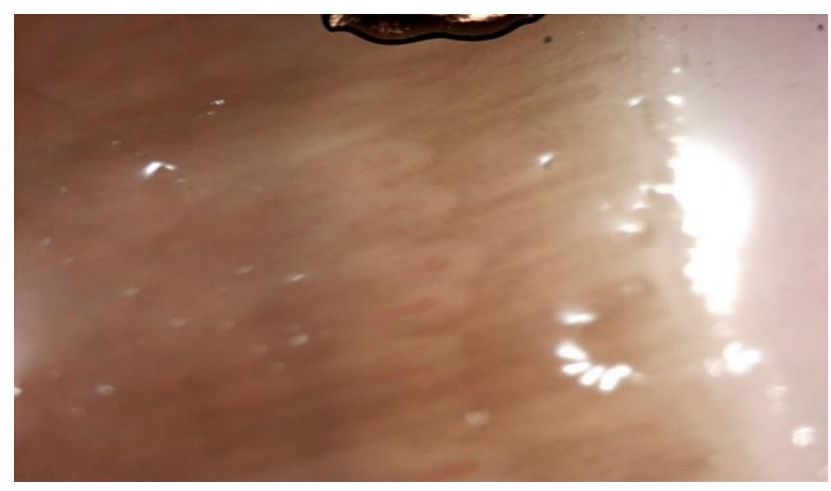

Figure 2: Nail bed under dermatoscope after application of oil.

\section{CONCLUSION}

This was the first study conducted in India to calculate the skin capillary density among pregnant participants. The present study showed that the skin capillary density significantly reduced in gestational hypertension or preeclampsia. PIH pregnant participants between 28-36 weeks of gestation having significantly lower skin capillary densities than normotensive counterparts. There is only a weak correlation between the severity of $\mathrm{PIH}$ and capillary density quantification. Further studies are needed to determine any possible correlation between skin capillary densities among hypertensive pregnant participants.

We conclude that estimating the skin capillary density provides a potentially useful clinical marker in the prediction of preeclampsia. Dermatoscope is an especially attractive clinical tool because it is entirely non-invasive, reproducible, and potentially cheap once the essential equipment is in place. The challenge is now to conduct a large clinical trial to validate dermatoscope as a novel clinical risk predictor so that it can be integrated in the routine clinical use.

\section{ACKNOWLEDGMENTS}

Authors would like to thank Professor Dr. Pravin N Mhatre and Dr. Vandana Bansal, Dr. Uday Khopkar, Dr. Amol Pawar, Dr, Hemraj Narkhede, and Dr, Noren for their extraordinary support in this project.

Funding: No funding sources

Conflict of interest: None declared

Ethical approval: The study was approved by the Institutional Ethics Committee

\section{REFERENCES}

1. Sibai B, Dekker G, Kupferminc M. Preeclampsia. Lancet Lond Eng. 2005;365(9461):785-99. 
2. Wagner SJ, Craici IM, Hogan MC, Bailey KR, Garovic VD. The effect of early diagnosis and treatment on maternal and fetal outcomes in patients with HELLP syndrome. Biochem Medica. 2007;17(1):61-70.

3. Meekins JW, Pijnenborg R, Hanssens M, McFadyen IR, van Asshe A. A study of placental bed spiral arteries and trophoblast invasion in normal and severe pre-eclamptic pregnancies. $\mathrm{Br} \mathrm{J}$ Obstet Gynaecol. 1994;101(8):669-74.

4. Baumwell S, Karumanchi SA. Pre-eclampsia: clinical manifestations and molecular mechanisms. Nephron Clin Pract. 2007;106(2):c72-81.

5. Hasan KM, Manyonda IT, Ng FS, Singer DR, Antonios TF. Skin capillary density changes in normal pregnancy and pre-eclampsia. J Hypertens. 2002;20(12):2439-43.

6. Antonios TFT, Singer DRJ, Markandu ND, Mortimer PS, MacGregor GA. Structural Skin Capillary Rarefaction in Essential Hypertension. Hypertens. 1999;33(4):998-1001.

7. Debbabi H, Uzan L, Mourad JJ, Safar M, Levy BI, Tibiriçà E. Increased skin capillary density in treated essential hypertensive patients. Am J Hypertens. 2006;19(5):477-83.

8. Antonios TFT, Rattray FM, Singer DRJ, Markandu ND, Mortimer PS, MacGregor GA. Rarefaction of skin capillaries in normotensive offspring of individuals with essential hypertension. Heart. 2003;89(2):175-8.

9. Kvehaugen AS, Dechend R, Ramstad HB, Troisi R, Fugelseth D, Staff AC. Endothelial Function and Circulating Biomarkers Are Disturbed in Women and Children After Preeclampsia. Hypertension. 2011;58(1):63-9.

10. Fraser GM, Morton JS, Schmidt SM, Bourque S, Davidge ST, Davenport MH, et al. Reduced uterine perfusion pressure decreases functional capillary density in skeletal muscle. Am J Physiol - Heart Circ Physiol. 2015;309(12):H2002-7.

11. Nama V, Manyonda IT, Onwude J, Antonios TF. Structural capillary rarefaction and the onset of preeclampsia. Obstet Gynecol. 2012;119(5):967-74.

12. Rusavy Z, Pitrova B, Korecko V, Kalis V. Changes in capillary diameters in pregnancy-induced hypertension. Hypertens Preg. 2015;34(3):307.

Cite this article as: Kumar M, Bansal V, Mhatre PN, Khopkar U. Skin capillary density in pregnancy induced hypertension and normotensive pregnant participants. Int J Reprod Contracept Obstet Gynecol 2018;7:4688-94. 